Proceeding of the $2^{\text {nd }}$ Scientific Conference on Women's Health

2-3 September 2020 - Hawler Medical University

\title{
Ischemic Heart Disease and Type A Behavior Pattern in Women in Kurdistan
}

Azad Ali Ismail ${ }^{1}$, Siamand Hassan Mohialdin $^{2}$, Balen Muhammad Muhammad ${ }^{3}$

\author{
1, 3 Koya University \\ 2 Hawler Medical University \\ Corresponding author: syamand.mohialdin@hmu.edu.krd
}

\begin{abstract}
Background and objective: Studies that addressed Ischemic heart disease's correlation and Type A behavior pattern reached inconclusive findings. This study aimed to determine the prevalence of type A behavior patterns among female IHD in the Iraqi Kurdistan region. This study also aimed to determine how certain demographic variables might be related to type A behavior pattern among this sample.
\end{abstract}

Methods: The sample consisted of 58 female heart patients recruited from hospitals in Hawler Teaching Hospital and Hawler heart center. The age of the non-random sample ranged from 22 to 90 years $(\mathrm{M}=57.36, \mathrm{SD}=14.26)$. Face-to-face interviews was conducted with each member. Type A personality scale, developed by Ismail (2008), was used for data collection. The scale was developed initially in Kurdish.

Results: The study found that the sample's mean score was 171.99 , with a standard deviation of 27.69. Except for high blood pressure, other demographic and health variables were not significantly related to type A behavior pattern among the sample.

Conclusion: The level of type A behavior pattern among women with heart IHD in Kurdistan is lower compared to healthy groups. Larger samples should be studied to confirm this finding further.

Keywords: Type A behavior pattern, IHD, Kurdistan

\section{INTRODUCTION}

Ischemia is defined as "inadequate blood supply (circulation) to a local area due to blockage of the blood vessels supplying the area. Ischemic means that an organ (e.g., the heart) is not getting enough blood and oxygen. Ischemic heart disease, also called coronary heart disease 


\section{Proceeding of the $2^{\text {nd }}$ Scientific Conference on Women's Health \\ 2-3 September 2020 - Hawler Medical University}

(CHD) or coronary artery disease, is the term given to heart problems caused by narrowed heart (coronary) arteries that supply blood to the heart muscle". ${ }^{1}$ Type A behavior pattern "refers to an individual who is involved in an aggressive and incessant struggle to achieve more and more in less and less time". ${ }^{2}$ Many studies ${ }^{3}$ had found an association between Type A behavior and coronary heart disease.

Rose $^{4}$ maintains that although it is generally accepted that the type A behavior pattern is a risk factor in the development of coronary artery disease (CAD), there have been conflicting results, primarily owing to differences in methods and CAD outcomes and inconsistencies associated with measuring the type A behavior pattern. As a result, researchers have begun to focus on subcomponents of the type A behavior pattern, particularly hostility and anger,

Friedman and Rosenman confirm that the epidemiological, clinical, and laboratory experimental data indicate without question that an significant association does exist between this behavior pattern and the prevalence ad incidence of coronary heart disease. ${ }^{5}$

Although it was established many decades ago that type A behavior is high among heart patients than the general population, no study has been conducted to confirm this relationship among Kurdish heart patients. This study aims to determine the prevalence of type A behavior pattern among a sample of heart patients in Hawler hospitals. Furthermore, the study aimed to determine the correlations between type A behavior and many demographic and health variables.

\section{METHODS}

Participants: The sample consisted of 58 female heart patients recruited from hospitals in Hawler Teaching Hospital and Hawler heart center. The age of the non-random sample ranged from 22 to 90 years $(M=57.36, S D=14.26)$. Face-to-face interviews was conducted with each member. Details of the sample are found in Table 1.

Instrument: Type A personality scale, developed by Ismail, ${ }^{6}$ was used for data collection. The scale was developed originally in Kurdish. The questionnaire consists of 68 items: 1 to 54 assess type A while items from 55-68 assess type B behavior pattern. For each item, there are five answering options: Apply to me to a considerable extent, apply to me to a large extent, apply to me to moderately, seldom apply to me, and do not apply to me. The scale has very good reliability using the test re-test technique. The correlation coefficient was very high (0.98), and using spilt-half techniques, and the correlation coefficient was high (0.82). 
Proceeding of the $2^{\text {nd }}$ Scientific Conference on Women's Health

2-3 September 2020 - Hawler Medical University

Table 1: Demographic characteristics of the sample

\begin{tabular}{cccc}
\hline & & Frequency & Percent \\
\hline \multirow{2}{*}{ Social status } & married & 36 & 63.2 \\
& divorced & 1 & 1.8 \\
& widow & 18 & 31.6 \\
& Missing & 2 & 3.5 \\
Job & house wife & 51 & 89.5 \\
& civil service & 3 & 5.3 \\
& retired & 3 & 5.3 \\
& low & 14 & 24.6 \\
& medium & 38 & 66.7 \\
& high & 4 & 7.0 \\
& Missing & 1 & 1.8 \\
& city & 33 & 57.9 \\
& town & 20 & 35.1 \\
& village & 3 & 5.3 \\
\hline
\end{tabular}

\section{RESULTS}

The study found that the sample's mean score on Type A behavior pattern was 171.99, with the standard deviation of 27.69. The study found that there is no correlation between age and Type A behavior pattern (Table 2).

Table 2: Age and Type A behavior pattern

\begin{tabular}{|cc|c|}
\hline & & Type A behavior \\
\hline Age & Pearson Correlation & -.188 \\
& Sig. (2-tailed) & .162 \\
$\mathrm{~N}$ & 57 \\
\hline
\end{tabular}

The job of the participant was also not correlated to their score on Type A behavior pattern questionnaire (Table 3) 


\section{Proceeding of the $2^{\text {nd }}$ Scientific Conference on Women's Health 2-3 September 2020 - Hawler Medical University}

Table 3: Type A behavior and job

\begin{tabular}{|l|c|c|c|c|c|}
\hline & Sum of Squares & df & Mean Square & F & Sig. \\
\hline Between Groups & 4280.19 & 2 & 2140.10 & 3.004 & .058 \\
Within Groups & 38467.57 & 54 & 712.36 & & \\
Total & 42747.77 & 56 & & & \\
\hline
\end{tabular}

However, high blood pressure was found to be significantly related to the type A behavior pattern among the sample (Table 4). The higher the blood pressure, the higher their score on the type A behavior scale.

Table 4: Blood pressure and type A behavior pattern

\begin{tabular}{|c|c|c|c|c|c|c|}
\hline & Blood pressure & $\mathrm{N}$ & Mean & Std. Deviation & $\mathrm{t}$ & Sig. \\
\hline \multirow[t]{2}{*}{ Type A behavior } & no & 26 & 180.10 & 20.14 & \multirow[t]{2}{*}{2.24} & \multirow[t]{2}{*}{$.02 *$} \\
\hline & yes & 31 & 164.18 & 31.10 & & \\
\hline
\end{tabular}

The study also found that Diabetes was not related to the type A behavior pattern among this study sample (Table 5). The weight was not correlated to this type of behavior either (Table $6)$.

Table 5: Diabetes and Type A behavior pattern

\begin{tabular}{|c|c|c|c|c|c|}
\hline Diabetes & $\mathrm{N}$ & Mean & Std. Deviation & $\mathrm{t}$ & Sig. \\
\hline Type A behavior no & 37 & 174.23 & 28.72 & 1.25 & .21 \\
yes & 18 & 164.17 & 25.83 & & \\
\hline
\end{tabular}

Table 6: Correlation between weight and Type A behavior pattern

\begin{tabular}{|ll|c|}
\hline & Type A behavior \\
\hline Weight & Pearson Correlation & -.080 \\
& Sig. (2-tailed) & .560 \\
& $\mathrm{~N}$ & 55 \\
\hline
\end{tabular}

Almost one fifth (19.3\%) of the sample reported smoking (Table 6). As for the number of cigarettes, $12.3 \%$ reported smoking 20 cigarettes and more daily (Table 7). 
Proceeding of the $2^{\text {nd }}$ Scientific Conference on Women's Health

2-3 September 2020 - Hawler Medical University

Table 6: Smoking among the participants

\begin{tabular}{|l|c|c|}
\hline Smoking & Frequency & Percent \\
\hline yes & 11 & 19.3 \\
no & 45 & 78.9 \\
In the past, but not now & 1 & 1.8 \\
Total & 57 & 100.0 \\
\hline
\end{tabular}

Table 7: Number of cigarettes smoked by the participants

\begin{tabular}{|l|c|c|}
\hline No. of cigarettes per day & Frequency & Percent \\
\hline .00 & 45 & 78.9 \\
2.00 & 1 & 1.8 \\
10.00 & 3 & 5.3 \\
15.00 & 1 & 1.8 \\
20.00 & 4 & 7.0 \\
40.00 & 2 & 3.5 \\
60.00 & 1 & 1.8 \\
Total & 57 & 100.0 \\
\hline
\end{tabular}

However, when the mean scores of smokers and nonsmokers were compared, the difference between them was not significant (Table 8).

Table 8: Difference between the mean scores of smokers and non smokers

\begin{tabular}{|l|c|c|c|c|c|c|}
\hline & Smoking & $\mathrm{N}$ & Mean & Deviation & $\mathrm{t}$ & Sig. \\
\hline Type & A yes & 11 & 164.60 & 34.28 & .82 & .41 \\
behavior & no & 45 & 172.15 & 25.47 & & \\
\hline
\end{tabular}

Although the majority of the respondents $(64.9 \%)$ did know whether their cholesterol level is high or low, the percentage of those with the high level was higher $(28.1 \%)$ compared to those with low level (7.0\%) (Table 9). 


\section{Proceeding of the $2^{\text {nd }}$ Scientific Conference on Women's Health 2-3 September 2020 - Hawler Medical University}

Table 9: Cholesterol level of the respondents

\begin{tabular}{|c|c|c|}
\hline Cholesterol level & Frequency & Percent \\
\hline not known & 37 & 64.9 \\
low & 4 & 7.0 \\
high & 16 & 28.1 \\
Total & 57 & 100.0 \\
\hline
\end{tabular}

When the mean scores of the respondents on the type A behavior pattern scale was compared based on their cholesterol level, large differences were found (Table 10). It seems those with low level of cholesterol had scored higher.

Table 10: Mean scores of the respondents according to their cholesterol level

\begin{tabular}{|l|c|c|c|}
\hline Cholesterol level & Mean & N & Std. Deviation \\
\hline not known & 172.82 & 37 & 28.18 \\
low & 203.50 & 4 & 17.46 \\
high & 160.24 & 16 & 21.65 \\
Total & 171.44 & 57 & 27.62 \\
\hline
\end{tabular}

The study used an analysis of variance to determine whether the difference between those with low cholesterol levels and high cholesterol levels. The result shows that the difference between those with low and high cholesterol levels was significant at .05 (Table 11).

Table 11: Analysis of variance for levels of cholesterol and type A behavior pattern

\begin{tabular}{|l|l|l|l|l|l|}
\hline & Sum of Squares & df & Mean Square & F & Sig. \\
\hline Between Groups & 6189.27 & 2 & 3094.63 & 4.57 & $.01^{*}$ \\
Within Groups & 36558.49 & 54 & 677.00 & & \\
Total & 42747.77 & 56 & & & \\
\hline
\end{tabular}

\section{DISCUSSION}

The study's main aim was to find out the prevalence of type A behavior pattern among a sample of heart patients in Hawler hospitals. Furthermore, the study aims to find out the correlations between type A behavior and many demographic and health variables. The 


\section{Proceeding of the $2{ }^{\text {nd }}$ Scientific Conference on Women's Health \\ 2-3 September 2020 - Hawler Medical University}

scores obtained by the sample were less compared to a younger and healthy sample in Ismail 6 study. Demographic variables, such as social status, age, occupation, economic status, and residence, were not correlated to type A behavior pattern.

Except for high blood pressure, other demographic and health variables were not significantly related to type A behavior pattern among the sample. Diabetes was not related to the type A behavior pattern. This result does not agree with Farhad, Hasan, and Rostam's (7) study, which found a significant relationship between personality type A and diabetes type 2 . It also does not agree with Rouland et al. study, which found that Type A Bortner scores were significantly higher in T1D patients than in T2D patients. ${ }^{8}$

Smoking was found not to be correlated to type A behavior pattern. This result is consistent with Hughes et al. study, which found that Type A and Type B smokers do not differ in smoking behavior or tobacco and nicotine intake. ${ }^{9}$ However, it does not agree with their researchers, who found a correlation between personality type and nicotine dependency. ${ }^{10}$

This study found a significant correlation between cholesterol level and type A behavior pattern. This result is consistent with Schwertner et al., who found an association between cholesterol was also significant for the subgroup of individuals with Type A-1 behavior patterns, but not for Type A-2, X, or B behavior patterns. ${ }^{11}$

Because the sample of this study was small on the one hand, and it was not randomly selected, it is difficult to generalize the study results on the population (patients with heart disease). This might also explain some of the differences between the current study results and some previous studies. Thus, bigger samples have to be studied to confirm the results of this study further.

\section{CONCLUSION}

The level of type A behavior pattern among women with heart IHD in Kurdistan is lower compared to healthy groups. Larger samples should be studied to confirm this finding further.

\section{REFERENCE}

1. IOM (Institute of Medicine). Cardiovascular disability: Updating the Social Security listings. Washington, DC: The National Academies Press; 2010.

2. Friedman, H.S. \& Booth-Kewley, S. Personality, Type A Behavior, and Coronary Heart Disease: The Role of Emotional Expression. Journal of Personality and Social Psychology 1987; 53(4): 783-792 
Proceeding of the $2^{\text {nd }}$ Scientific Conference on Women's Health

2-3 September 2020 - Hawler Medical University

3. Bennett, P. \& Carroll, D. Type A Behaviours and Heart Disease: Epidemiological and Experimental Foundations, Behavioural Neurology 1990; 3, 261-277.

4. Rose, I. M. Type A behaviour pattern: a concept revisited CMAJ 1987; 136, FEBRUARY 15

5. Friedman, M. \& Rosenman, R.H. Type A Behavior Pattern: Its Association with Coronary Heart Disease, Journal of Holistic Medicine 1986; 1(1), https://doi.org/10.3109/13561828609038119

6. Ismail, G.A. Parents treatment styles and their relation to personality pattern A/B among students of the University of Sulaimani. Unpublished Master thesis 2008.

7. Farhad, F., Hasan, A., and Rostam, J. The Association of Personality Type A and B to Type 2 Diabetes Mellitus in Patients Referring to Diabetes Center, Kermanshah, Journal of Clinical Research in Paramedical Sciences 2015; 4 (3): 188-194.

8. Rouland, A., Chauvet-Gelinier,J-C., Sberna,A-L., Crevisy,E., Buffier,P., Mouillot,T., Petit,J-M., and Vergès, B. Personality types in individuals with type 1 and type 2 diabetes, Endocr Connect 2020; 9(3): 254-260. doi: 10.1530/EC-19-0499

9. Hughes, J.R., Pickens, R.W., Gust, S.W., Hatsukami, D.K., and Svikis, D.S. Smoking behavior of type A and type B smokers, Addictive Behavior 1986; 11(2):115-8. doi: 10.1016/0306-4603(86)90035-3

10. Bakshi, H. and Khodadadizadeh, A. Personality types and nicotine dependency among medical sciences students, Internet Journal of Medical Update 2013; 8(2):1015.

11. Schwertner, H.A., Troxler, R.G., Uhl, G.S., \& Jackson, W.G. Relationship between Cortisol and Cholesterol in Men with Coronary Artery Disease and Type A Behavior, Arteriosclerosis 1984; 4:59-64. 